\title{
ESTUDO DA CORROSÃO ÁCIDA DE FERRO FUNDIDO CINZENTO E AÇO VISANDO A PRODUÇÃO DE HIDROGÊNIO
}

\author{
P.O.B.FERREIRA ${ }^{1}$, A. F. LIMA ${ }^{1}$ e S.C. DANTAS ${ }^{1}$ \\ ${ }^{1}$ Universidade Federal Do Triângulo Mineiro, Faculdade de Engenharia Química \\ E-mail para contato: sandra@icte.uftm.edu.br
}

\begin{abstract}
RESUMO - O metal é um dos produtos mais utilizados nas tarefas do dia-a-dia, sendo que diariamente são descartados milhares de toneladas no meio ambiente. Pensando nisso, e usando a corrosão como base de estudo, decidiu-se buscar materiais inutilizados, como o ferro, que ao entrarem em contato com um ácido passariam por um processo de corrosão gerando como produto o hidrogênio. $\mathrm{O}$ material escolhido foi parte de um carro que estava em um ferro velho, sabe-se que o mesmo é formado de diferentes componentes como aço e ferro fundido cinzento, que podem ser encontrados na lataria e no disco de freio, respectivamente. Assim, utilizando como material o aço, ferro fundido cinzento e ácido clorídrico com diferentes molaridades, foi possível fazer um estudo variando e combinando o material ferroso, ácido e tempo. Após os testes laboratoriais, foi feita a análise dos resultados verificando a influência do tempo e do ácido para os diferentes materiais. Ocorrida a reação, e com base na estequiometria, será possível quantificar a massa de ferro perdida.
\end{abstract}

\section{INTRODUÇÃO}

Os metais ferrosos mais comuns são o aço e o ferro fundido. Esses metais são ligas de ferro e carbono, que podem ainda apresentar na sua composição elementos como fósforo, manganês, silício, cobre, enxofre, entre outros. A rigor, possuem uma porcentagem de ferro superior a 90\%, daí a denominação de metais ferrosos (Ecosucatas, 2015). Tais metais estão sujeitos a todo o momento à corrosão, que é a deterioração de um material por ação química ou eletroquímica do meio ambiente associada ou não a esforços mecânicos (Corrosão de metais, 2015).

Quando o metal é colocado no meio ácido, acontece sobre o metal uma distribuição de áreas anódicas e catódicas, ocorrendo a corrosão deste. Nas áreas anódicas o metal se oxida e nas catódicas o íon hidrogênio, se reduz ocorrendo o desprendimento de gás hidrogênio. Essa reação é frequentemente representada como a Equação 1 (Gentil, 2012)

$$
2 \mathrm{H}^{+}+2 e \rightarrow \mathrm{H}_{2}
$$

E se o ferro, presente no metal, é atacado pelo ácido clorídrico desprende hidrogênio, como representado pela reação de oxirredução (Gentil, 2012):

$$
\mathrm{Fe}+2 \mathrm{HCl} \rightarrow \mathrm{FeCl}_{2}+\mathrm{H}_{2}
$$


Essa reação representa o ataque de ferro metálico por ácidos não oxidantes, isto é, que não têm caráter oxidante na sua parte aniônica.

Deste modo, o presente trabalho teve como objetivo verificar o comportamento com o tempo, do aço e do ferro fundido cinzento quando submetidos à reação de corrosão ácida, utilizando ácido clorídrico com duas concentrações distintas. Ocorrida a reação, deseja-se quantificar a massa de ferro perdida por meio do método gravimétrico.

\section{PROCEDIMENTO EXPERIMENTAL}

Para a realização dos experimentos foram utilizados pedaços de aproximadamente $1,5 \mathrm{~cm} \times 1,5 \mathrm{~cm}$ de ferro fundido cinzento obtido pelo corte de um disco de freio e pedaços de aço obtido pelo corte da lataria de um carro, cada um com sua devida espessura. Os experimentos foram realizados à temperatura ambiente e com solução de ácido clorídrico nas concentrações de 0,5 e $1,0 \mathrm{~mol} / 1$.

As amostras foram lavadas com palha de aço e a parte da lataria foi polida, para que a tinta ainda restante fosse retirada. Já no laboratório lavaram-se os pedaços com água destilada e esses foram colocados por 10 minutos em uma estufa.

Preparou-se utilizando uma proveta, 8 béqueres contendo $20 \mathrm{ml}$ de ácido. Os pedaços foram pesados em uma balança analítica e colocados em seus respectivos béqueres. Disparouse o cronômetro e a cada 10 minutos os pedaços foram retirados da solução com o auxílio de uma pinça. Os pedaços foram lavados com água destilada e levados para estufa por 10 minutos, esperou-se um tempo para que esfriassem e foram pesados novamente para que a perda de massa fosse obtida. Esse método foi realizado da mesma maneira para os diferentes ferros e ácidos, sendo o tempo de duração para cada experimento de 80 minutos.

\section{RESULTADOS E DISCUSSÕES}

Inicialmente observou-se que os pedaços de freio apresentavam geometrias diferentes, sendo que alguns tinham forma regulares (quadradas ou retangulares) e outros eram irregulares contendo pontas. Para o primeiro experimento, decidiu-se pegar aleatoriamente os pedaços para realização do método gravimétrico (não apresentado). Com os dados obtidos da perda de massa, notou-se que os pedaços com diferentes geometrias apresentaram comportamentos diferentes. Com isso, os pedaços foram separados de acordo com a geometria e utilizados em experimentos diferentes. Para os demais experimentos, decidiu-se utilizar somente pedaços do disco de freio irregulares, devido à maior quantidade dessas peças em relação aos regulares.

A Figura 1.A relaciona o comportamento da perda de massa dos pedaços de freio com formato regular e irregular. Observa-se que o freio com pedaços irregulares apresenta uma perda de massa muito maior e que ambos seguem um comportamento linear, porém com um ângulo de inclinação diferente. Sabe-se que o disco de freio possui uma parte central, chamada de cubo de roda, que fica em contato direto com a roda e todas as vezes que a frenagem é realizada, o cilindro mestre entra em contato com as pastilhas. Esse acionamento faz com que ocorra um atrito da roda com o cubo da roda, causando um maior desgaste nessa parte em relação às outras do disco, esse desgaste deixa a parte central mais sujeita à corrosão. 
Observou-se que os pedaços irregulares contém um pequeno pedaço da parte que estava em contato direto com o cubo de roda, e os regulares são os pedaços que foram cortados do restante do disco. Com base nessas informações, pode-se explicar o comportamento obtido pela Figura 1 A. Os pedaços irregulares eram formados por uma parte em que o processo de corrosão já havia se iniciado, portanto a perda de massa com o tempo foi maior do que nos regulares, nos quais o processo de corrosão só teve início com a imersão dos pedaços em ácido, sendo necessária a quebra de alguma camada de filme protetor que não existia na parte em que a corrosão já havia se iniciado.

Além disso, levando em conta a morfologia dos pedaços, sabe-se que peças irregulares tem uma superfície menos lisa ou mais rugosa tornando a superfície de contato maior, acelerando a corrosão. Portanto, os pedaços regulares tendo uma menor superfície de contato apresentam uma menor perda de massa com o tempo.

Para uma possível comparação do comportamento da perda de massa em relação aos pedaços que já haviam sido colocados em ácido (com concentração de $0,5 \mathrm{~mol} / \mathrm{L}$ ), resolveu-se polir os pedaços de freio para imersão no meio corrosivo novamente (Figura 1.B). Observa-se uma discrepância entre os valores obtidos para o freio já utilizado. Além disso, verifica-se que o freio irregular polido tem maior perda de massa que o freio irregular que já foi usado em experimentos anteriores, porém, inicialmente a perda de massa é praticamente a mesma.

Figura 1 - Perda de massa em função do tempo de reação para (A) diferentes geometrias imersas em $\mathrm{HCl}$ 0,5 mol/L; (B) freio polido e usado imersos em $\mathrm{HCl}$ 1,0 mol/L.

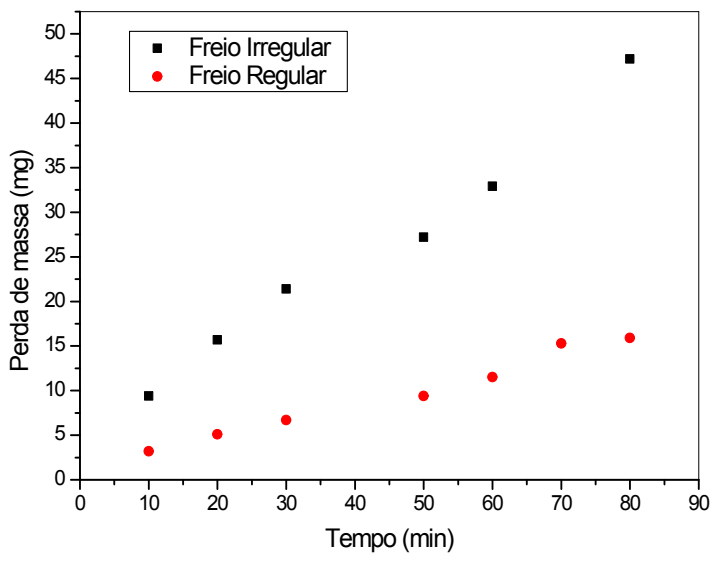

(A)

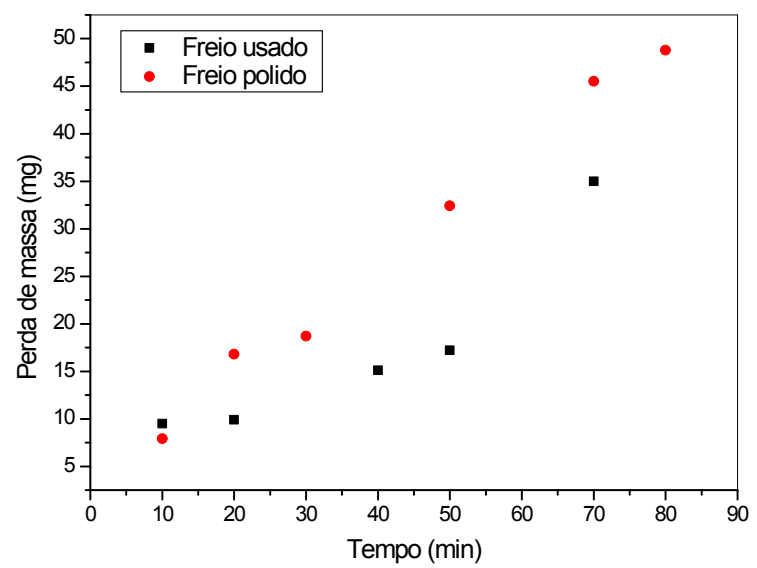

(B)

O comportamento discrepante dos resultados obtidos para o freio irregular que já havia sido utilizado na solução de $\mathrm{HCl}$ com concentração de $0,5 \mathrm{~mol} / \mathrm{L}$, pode ser explicado pelo fato de que, se um metal for retirado de um ácido com uma determinada concentração e colocado no mesmo ácido só que com uma concentração diferente, ele poderá não ser mais atacado, diz-se que o metal está no estado passivo (Gentil, 2012). A passividade é causada por um filme muito fino de óxido na superfície metálica ou por um estado oxidado da superfície, que impede o contato entre o metal e o meio corrosivo. Admite-se ainda, a possibilidade de ocorrer a passivação por causa de oxigênio, íons ou moléculas, adsorvidas na superfície metálica. Esta pode ser destruída por substâncias redutoras, ou por um leve choque para destruir a película, como por exemplo, no jateamento abrasivo, ou seja, o polimento do metal (Gentil, 2012). A maior perda de massa obtida para o freio polido é esperada, pois quando 
ocorre a limpeza de um material usando um jateamento abrasivo, retiram-se todas as impurezas e camadas protetoras que poderiam existir, podendo criar também, lacunas que favorecerão a corrosão, com isso, o metal fica mais sujeito ao ataque ácido, assim a velocidade de corrosão será maior.

Comparou-se também a influência das concentrações dos ácidos em relação à perda de massa para a lataria e o freio separadamente, como pode ser observado nas Figuras 2.

Figura 2 - Perda de massa em função do tempo de reação para diferentes concentrações de $\mathrm{HCl}$ para (A) lataria e (B) freio.

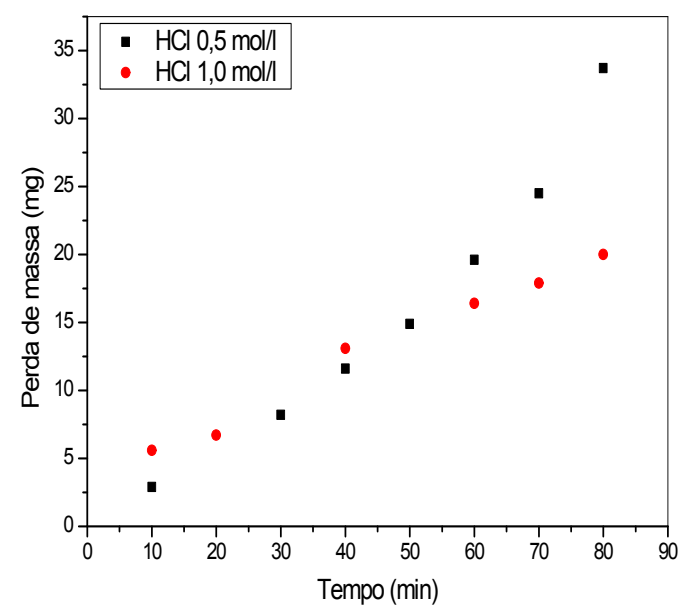

(A)

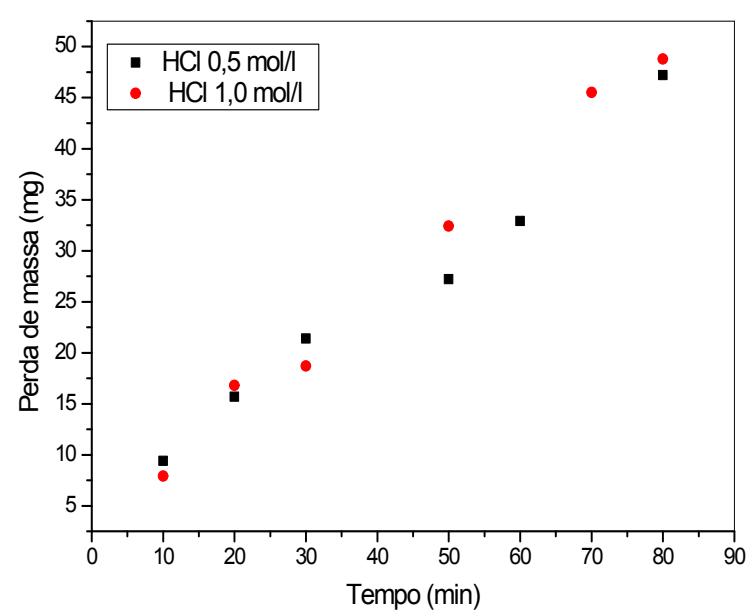

(B)

Através da Figura 2.A, nota-se que, para o ácido clorídrico menos concentrado obtêm-se uma maior perda de massa, sendo que no último tempo analisado, esta perda é 1,5 vezes maior para a menor concentração. Apenas para os tempos mais baixos a perda foi maior para a maior concentração. Quanto à Figura 2.B, nota-se que ocorre uma variação da maior perda de massa em pontos aleatórios para o ácido na maior e menor concentração.

De acordo com a literatura, experimentalmente, observa-se que alguns metais podem apresentar comportamento diferente do que seria previsto pelas suas posições na tabela de potenciais. Assim, o ferro pode ser rapidamente atacado por um ácido diluído, mas não é pelo concentrado, como ocorre no caso do $\mathrm{HNO}_{3}$ (Gentil, 2012). Quando isso ocorre, diz-se que o metal está no estado passivo. Nas condições em que o material se torna passivo, seu comportamento eletroquímico revela um potencial mais nobre, isto é, menos ativo que o normalmente apresentado. O material sofre então corrosão mais lenta. Sabendo que foram utilizados materiais diferentes e que a passivação é um processo que depende do material e do meio, o comportamento da Figura 2.A pode ser justificado pela citação à cima. Devido ao comportamento dos dados obtidos para o freio irregular (Figura 2.B), não se pode afirmar que ocorreu a passivação neste caso, para se ter certeza deveriam ser feitos novos experimentos.

Sabendo que a diferença de peso do freio e da lataria é grande, para uma possível comparação entre a perda de massa entre eles, foi necessário obter a porcentagem de perda de massa, a qual foi determinada segundo a Equação 3: 


$$
\left\lfloor 1-\frac{\text { massa final }}{\text { massa inicial }}\right\rfloor \cdot 100
$$

Figura 3- Comportamento perda de massa do freio e lataria imersos em (A) $\mathrm{HCl} 1,0 \mathrm{~mol} / \mathrm{l} \mathrm{e}$ (B) $\mathrm{HCl} 0,5 \mathrm{~mol} / \mathrm{l}$

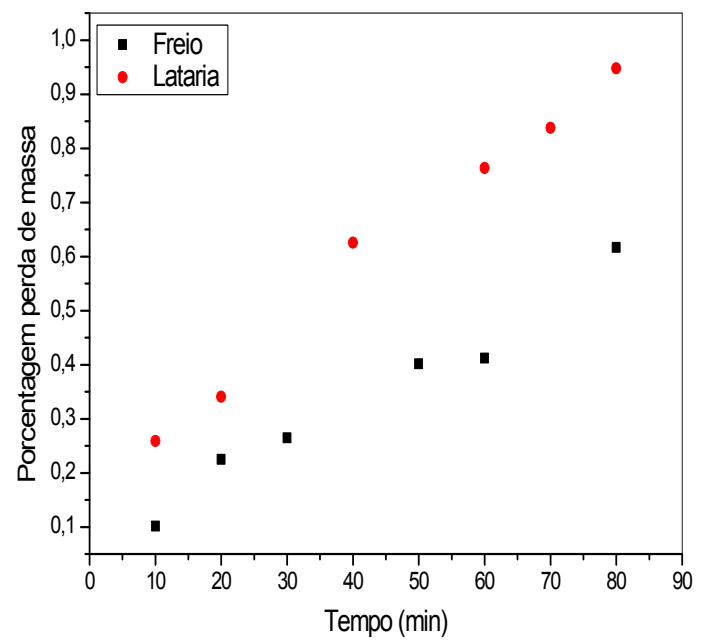

(A)

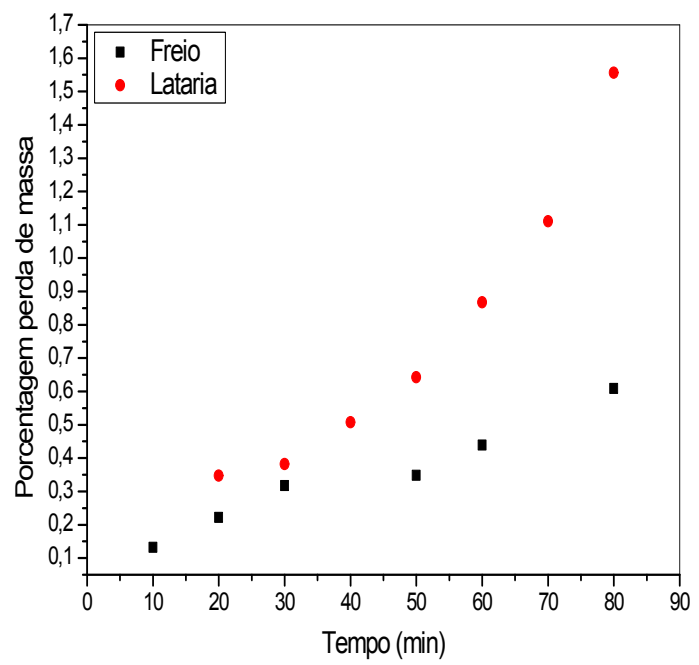

(B)

De acordo com a Figura 3, é possível verificar que a lataria apresenta uma maior perda de massa em relação ao disco de freio para ambas as concentrações de $\mathrm{HCl}$, ou seja, o aço tem maior tendência à corrosão em meio ácido do que o ferro fundido cinzento. Observa-se que na Figura3.A essa diferença segue de forma quase constante e na Figura3.B a diferença dos valores de perda de massa para o freio e lataria, tendem a aumentar com o tempo, sendo no ultimo ponto bem maior. Esta é causada pela diferença do comportamento obtido, pois, a lataria apresenta um comportamento curvo e o freio linear.

Levando em conta a composição química do disco de freio e lataria, não se pode afirmar quais são os compostos presentes e nem suas porcentagens em liga, pois cada fabricante automobilístico leva em conta uma determinada composição, que não pode ser revelada. $\mathrm{O}$ disco de freio por sofrer um maior desgaste devido à frenagem, como citado anteriormente, é composto sempre por elementos de liga como $\mathrm{Si}$ e $\mathrm{Cr}$, que são adicionados visando uma menor corrosão. Quanto à lataria, por ser revestida por uma camada de tinta, ou seja, por conter inibidores de corrosão, pode ou não apresentar esses elementos (Colpaert, 2008). Para a lataria, como a camada protetora, a tinta, foi retirada por polimento, o aço fícou desprotegido, enquanto que os elementos de liga presentes no disco de freio continuaram influenciando a inibição da corrosão do disco de freio. Assim, a maior corrosão da lataria para os ácidos de diferentes concentrações, pode ser justificada.

Considerando também a parte visual, que pôde ser observada durante a parte experimental, a coloração do freio usado pela primeira vez não mudou após a imersão em ácido, já o freio que foi polido para reuso teve alteração. Como foi necessário polir todos os pedaços da lataria, para retirar a tinta superficial, todos os pedaços apresentaram diferenças na coloração após a imersão. E no que diz respeito à parte de resíduos depositados no fundo do 
béquer, o freio com pedaços regulares apresentaram pouca quantidade, os pedaços irregulares apresentaram uma quantidade significativa de resíduos, a qual foi maior utilizando o material não polido, pois quando polido, a quantidade de resíduos depositados foi semelhante à quantidade observada nos pedaços de freio regular. Quanto aos pedaços da lataria, a solução resultante após cada tempo, não apresentou nenhum resíduo visível, já que a lataria após o polimento tinha uma cor cinza, o que dificultou na visualização dos possíveis resíduos.

\section{CONCLUSÃO}

Conclui-se que a parte experimental foi de fácil realização, porém foi necessário muito estudo para justificar os dados e os comportamentos gráficos obtidos. Além disso, o estudo da corrosão é relativamente difícil, pois a taxa de corrosão é determinada por um número de questões complexas que envolvem, por exemplo, a composição química dos materiais estudados, a formação de camadas passivadoras, adsorção de íons e do próprio hidrogênio gerado como produto de reação da corrosão ácida.

Durante e após o experimento, foram obtidos resultados inesperados como a grande influência na perda de massa devido à diferença da geometria e superfície de contato, a maior perda de massa obtida quando utilizado o ácido com a menor concentração, influência nos dados obtidos quando os pedaços foram reutilizados e também quando foram polidos.

\section{REFERÊNCIAS}

CORROSÃO DE METAIS. Disponível em: http://www.coladaweb.com/quimica/fisicoquimica/corrosao-de-metais Acesso em 18/03/2015.

ECOSUCATAS. Materiais ferrosos. Disponível em: http://www.ecosucatas.com.br/metaisferrosos.html . Acesso em 18/03/2015.

GENTIL, Vicente. Corrosão. Rio de Janeiro: LTC, 2012, $6^{\text {a }}$ ed.

COLPAERT, Hubertus. Metalografia. São Paulo: Blucher, 2008, $4^{\text {a }} \mathrm{ed}$. 